\title{
Evaluating Isolation Behaviors by Nurses Using Mobile Computer Workstations at the Bedside.
}

\author{
Elizabeth L. Beam \\ University of Nebraska Medical Center, ebeam@unmc.edu
}

Shawn G. Gibbs

Indiana University - Bloomington

Angela L. Hewlett

University of Nebraska Medical Center, Department of Internal Medicine, Division of Infectious Diseases, alhewlett@unmc.edu

Peter C. Iwen

University of Nebraska Medical Center, piwen@unmc.edu

Suzanne L. Nuss

Nebraska Medicine, sInuss@nebraskamed.com

See next page for additional authors

Tell us how you used this information in this short survey.

Follow this and additional works at: https://digitalcommons.unmc.edu/con_articles

Part of the Nursing Commons

\section{Recommended Citation}

Beam, Elizabeth L.; Gibbs, Shawn G.; Hewlett, Angela L.; Iwen, Peter C.; Nuss, Suzanne L.; and Smith, Philip W., "Evaluating Isolation Behaviors by Nurses Using Mobile Computer Workstations at the Bedside."

(2016). Journal Articles: College of Nursing. 25.

https://digitalcommons.unmc.edu/con_articles/25

This Article is brought to you for free and open access by the College of Nursing at DigitalCommons@UNMC. It has been accepted for inclusion in Journal Articles: College of Nursing by an authorized administrator of DigitalCommons@UNMC. For more information, please contact digitalcommons@unmc.edu. 


\section{Authors}

Elizabeth L. Beam, Shawn G. Gibbs, Angela L. Hewlett, Peter C. Iwen, Suzanne L. Nuss, and Philip W. Smith

This article is available at DigitalCommons@UNMC: https://digitalcommons.unmc.edu/con_articles/25 
This document is the Accepted Manuscript of *Beam, E. L., Gibbs, S. G., Hewlett, A. L., Iwen, P. C., Nuss, S. L., \& Smith, P. W. (2016). Evaluating isolation behaviors by nurses using mobile computer workstations at the bedside. Computers, Informatics, Nursing, 34(9), 387-

392. https://doi.org/10.1097/cin.0000000000000248

Title: Evaluating isolation behaviors by nurses utilizing mobile computer workstations at the bedside

Authors: *Elizabeth L. Beam, MSN, RN, University of Nebraska Medical Center (UNMC) College of Nursing, Omaha, NE, US; Shawn G. Gibbs, PhD, Indiana University School of Public Health, Environmental Health, Bloomington, IN, US; Angela L. Hewlett, MD, UNMC College of Medicine, Infectious Diseases, Omaha, NE, US; Peter C. Iwen, PhD, UNMC College of Medicine, Pathology/Microbiology, Omaha, NE, US; Suzanne L. Nuss, PhD, RN, The Nebraska Medical Center, Director for Care Transitions and Nursing Outcomes, Omaha, NE, US; Philip W. Smith, MD, UNMC College of Medicine, Infectious Diseases, Omaha, NE, US

*Corresponding Author Information: Elizabeth L. Beam, MSN, RN, 985330 Nebraska Medical Center, Omaha, NE 68198-5330, W: 402-559-6547, F: 402-559-6847, E: ebeam@unmc.edu

Keywords: Computer, Isolation, Nursing

Financial support. None reported.

Potential conflicts of interest. All authors report no conflicts of interest relevant to this article. Acknowledgements: Eleanor Rogan, PhD for support and guidance through my graduate work, Stephen Smith for study technical support, Andrea Gaydess who acted as the standardized patient, Shelly Schwedhelm for donating use of some equipment and recruitment support, Kate Boulter for coordinating use of the Nebraska Biocontainment Patient Care Unit, and Aurora Le for her assistance with editing. 
Evaluating isolation behaviors by nurses utilizing mobile computer workstations at the bedside

\begin{abstract}
:
This secondary analysis from a larger mixed methods study with a sequential explanatory design investigates the clinical challenges for nurses providing patient care, in an airborne and contact isolation room, while using a computer on wheels (COW) for medication administration in a simulated setting. A hospital room in a large Midwestern healthcare center was used to create the simulation experience. Registered nurses, who regularly work in clinical care at the patient bedside, were recruited as study participants in the simulation and debriefing experience. A live volunteer acted as the standardized patient who needed assessment and intravenous pain medication. The simulation was video recorded to observe participating nurses conducting patient care in an airborne and contact isolation room. Participants then reviewed their performance with study personnel in a formal, audio recorded debriefing. Isolation behaviors were scored and the debriefing sessions were analyzed. Considerable variation was found in behaviors related to using a COW while caring for an isolation patient. Currently, no nursing care guidelines exist on the use of COWs in an airborne and contact isolation room. Specific education is needed on nursing care processes for the proper disinfection of COWs and to reduce the potential for disease transmission from environmental contamination.
\end{abstract}


Evaluating isolation behaviors by nurses utilizing mobile computer workstations at the bedside Computers are an essential component of today's healthcare systems. While the computer instantly brings data to the bedside and helps to optimize patient care, the equipment itself poses infection control challenges for proper use and disinfection. Recommendations for disinfecting computer equipment emerged in the literature as computers became more common at the bedside. ${ }^{1,2}$ Computer keyboards, specifically, have been shown to be contaminated with pathogens related to healthcare-associated infection such as Streptococcus, Clostridium perfringens, Enterococcus, Staphylococcus aureus, fungi, and gram-negative organisms. ${ }^{3,4}$ Placing a computer on wheels (COW) has become a common occurrence in healthcare settings today, as they are used for bedside charting of health assessments and serve as a vehicle for medication administration. Nurses are the frontline workers using these technologies at the bedside. The COWs typically consist of laptops fastened to a wheeled cart or workstation. This mobility creates additional challenges for preventing the spread of hospital acquired infections and the need to know the appropriate techniques to clean such equipment. Education and evaluation of surface cleaning has been shown to dramatically improve the methods for disinfection of keyboards on COWs in the clinical setting. ${ }^{5}$

There is increasing evidence that contaminated surfaces in hospitals can transmit disease between patients ${ }^{6}$ and routine environmental disinfection of high-touch surfaces can notably reduce transmission and infection rates. ${ }^{7}$ The decontamination and disinfection processes of high-touch surfaces is complicated by many variables such as: the type of cloth used, how much disinfectant should be applied, the amount of friction, appropriate surface areas to clean, and drying times. ${ }^{8}$ Maintaining the cleanliness of computers and portable medical equipment has been shown to be a challenge for healthcare workers, which indicates the need for increased 
education on disinfection processes. ${ }^{9,10}$ With a plethora of portable equipment in hospitals, the task of cleaning specific hospital room items is often designated to either housekeeping or the nursing staff.

Nurses commonly use isolation behaviors to care for patients. These isolation behaviors often include the proper use of personal protective equipment, performing hand hygiene, and decontaminating surfaces. Aforementioned, the $\mathrm{COW}$ is not only critical in accessing electronic health records and recording vitals, it is also an essential tool in the safe administration of medications. In many hospital units, a nurse is assigned a COW for the entire shift and frequently there are not enough computers to have a dedicated $\mathrm{COW}$ in each isolation room. This leads to the clinical challenge of entering and exiting the isolation room with the COW.

This study used a simulated patient care scenario to investigate common isolation behaviors with a COW for patients in isolation, as part of a larger study on evaluating infection control behaviors in nurses. ${ }^{11}$ The purpose of this study was to identify infection control behaviors performed by nurses which may or may not adhere to clinical standards for isolation practice while working with a COW in the care of a patient in airborne and contact precautions. The theoretical framework for this research combined the reflective practice work of Donald Schön ${ }^{12}$ using discrete video recording with a retrospective "think aloud" process ${ }^{13}$ for capturing the rationales for clinical behaviors from the nurses who participated.

\section{Methods}

This secondary analysis, from a larger mixed methods study with a sequential explanatory design, investigates the clinical challenges for nurses providing patient care, in an airborne and contact isolation room, while using a computer on wheels (COW) for medication administration in a simulated setting. This research study was approved by the University of 
Nebraska Medical Center Institutional Review Board by expedited review, and it was approved as (IRB \#450-12-EP). ${ }^{11} \mathrm{~A}$ hospital room in an academic medical center with 621 licensed beds was used to create the simulation experience. Utilizing a clinical scenario from a previous study, ${ }^{14}$ a live volunteer acted as the simulated patient. The simulated patient wore a hospital gown and hospital armband. An intravenous line was attached under the sleeve of the gown, which allowed the continuous fluids to drip into an empty bag under the sheets of the hospital bed. The necessary isolation for the patient's condition in the scenario was determined to be standard airborne and contact precautions. The patient care scenario involved conducting the initial patient assessment and administering an intravenous two milligram dose of morphine sulfate. A typical isolation cart with personal protective equipment (PPE) was available to the nurses at the door to the patient room. The signage for airborne and contact precautions was also posted at the door. Study personnel explained the care scenario and introduced the nurse to the hospital room before the simulation began, so the nurse could ask any questions before the simulation started. When the nurse was ready to begin the simulation, a digital camera on a tripod recorded hallway activities and two small High Definition (HD) cameras attached to the ceiling inside the room were activated to record the in-room patient care activities.

A COW was available to the study participants in the hallway, outside the patient room. Nurses were encouraged to use the COW as they would in their nursing unit. Thus if the nurses worked in a unit where each hospital room had its own computer, the COW would remain in the patient room for the simulation. If the nurses worked in a unit where COWs were taken from patient room to patient room with the nurse, they were encouraged to provide the care to the simulated patient in the manner to which they were accustomed. 
The COW was a laptop connected to a wheeled cart with panels to hold the keyboard and mouse. The cart also had baskets and a holder for the barcode scanner (Figure 1). The hospital uses an electronic medical record (EMR) for patients who are admitted. For the scenario, even though the simulated patient did not have a record in the EMR, the nurses were told to ad-lib patient data entry into the EMR as they participated in the patient care simulation. This meant the nurse typed on the keyboard to activate the physician's order, scanned the armband and syringe, and finally administered the medication even though the computer was not responsive to any typing or scanning.

Once the simulation was completed, nurses were individually shown the video recording of their performance in a private area. They were asked to "think aloud" as they reviewed the video, commenting on their own behaviors related to isolation care. ${ }^{13}$ Nurses were specifically cued to speak on their knowledge related to disinfection of computer workstations during the debriefing. The debriefing session was audio recorded and transcribed for further qualitative analysis. One month following the simulation experience, a link, directing to a three-question survey, was emailed to each study participant asking the nurses to comment about changes in clinical practice, the timing of those clinical practice changes, and continued clinical challenges.

The research team later scored the video recordings to evaluate the quality of isolation care behaviors. A more detailed analysis of behaviors directly related to the use of the COW going in and out of the isolation room was conducted.

\section{Results}

Twenty-four nurses participated in the larger study, but only eighteen nurses brought the $\mathrm{COW}$ in and out of the patient room as part of the patient care scenario. This analysis will focus on those eighteen study participants. The study sample is described in Table 1. 
Behaviors specific to entering the room with the $\mathrm{COW}$ and providing patient care were analyzed. None of the nurses in the study deliberately wiped down the COW before entering the room, although disinfectant wipes were readily available. During the debriefing session two of the nurses stated they assumed the COW was clean in the scenario. Fifteen of the nurses $(83.3 \%)$ had physical contact with the patient, during the physical assessment, before returning to the COW for the administration of pain medication, potentially contaminating the COW surfaces. Three nurses (16.7\%) gave the simulated two milligram dose of morphine sulfate using the COW first, and then proceeded to do the physical exam. One of these three nurses specifically described prioritizing the pain medication administration to keep the COW as clean as possible. Of the three who prioritized medication administration, two nurses touched their mask or other objects in the room before using the COW, conceivably contaminated their gloves before conducting the medication administration procedure.

Integrating methods to safely exit the patient room with the COW in conjunction with the PPE doffing process led to some challenges for the nurses (Table 2). Fifteen nurses (83.3\%) kept the COW in their presence upon exit of the patient room, but on three occasions the COW was sent out of the room unattended and dirty, before the nurse closed the door and doffed their PPE. The COW was unattended in all three cases until the nurse emerged from the patient room to do the disinfection. The times that the COW was left unattended in the hallway ranged from 20 to 40 seconds. There were several variations in practice related to hand hygiene in the transition from removing isolation PPE to COW disinfection. Only one nurse (5.5\%) left the room after doffing the isolation PPE, with no hand hygiene or donning of new gloves, before touching the COW. Eight (44.4\%) performed hand hygiene alone between removing their isolation PPE and touching the COW. Two nurses (11.1\%) used hand sanitizer, followed by donning new gloves 
between removing their isolation PPE and touching the COW. Five nurses (27.8\%) used gloves, alone, between removing the isolation PPE and touching the COW. All together seven of the nurses $(38.9 \%)$ donned new gloves for the disinfection of the COW. Three nurses obtained their gloves in the room, while the other four got the gloves from the isolation cart. Of those four nurses, only one used hand sanitizer before reaching into the clean cart; nevertheless the nurse still contaminated his/her hands with a dirty mask before reaching into the isolation cart for the new gloves.

Two of the nurses $(11.1 \%)$ that participated in the study did not make any attempt to disinfect the COW upon leaving the patient room. During the debriefing session, one of these nurses stated, "So I have to admit, maybe, if I were like in real life going in and out of an isolation room if I had like floated I might have cleaned off my computer, but I know that like ordinarily when I go in and out, I don't clean off my computer between patient rooms." The other nurse recognized his/her lack of COW disinfection in the review of the video recording. The nurse described how taking a COW in and out of a patient room is not a normal process in the unit where he/she normally provides patient care. This nurse discussed commonly using disinfection wipes to clean other portable medical equipment, like thermometers or glucose meters, when those items are used and transferred from room to room. Although all nurses in the study were provided the same study introduction and direction on COW use for the simulation in terms of taking the COW in and out of the room, in this case a misunderstanding occurred and the nurse utilized the COW in a mobile fashion for the simulation.

Of the 16 nurses $(88.9 \%)$ who disinfected the COW after use, all of them performed the disinfection process outside of the patient room. Despite this, one nurse verbalized that cleaning the COW on their unit was normally done in the patient room. Nurses disinfected the COW in 
areas that they felt were contaminated in patient care such as the mouse, the barcode wand, the keyboard, and the cart's top surface (Table 3). The screen, cords, and cart base were wiped off much less frequently. No measures of wiping quality were recorded in this study beyond the video recording, but the wiping was rarely for more than a few seconds and with little friction or force applied.

In the debriefing, nurses were cued to talk about any education they receive related to COW disinfection. Nine nurses stated they were told to wipe the COWs down with disinfectant wipes in their unit, but no specific directions or protocols were given. One nurse stated that cleaning the COWs is a component of annual competency training delivered through an online learning management system. In the survey conducted one month after the simulation experience, three of the 18 nurses evaluated (16.7\%) made comments related to the COW when asked about continued clinical challenges. Two noted concerns related to ensuring that portable equipment used from room to room is properly disinfected. Another specifically mentioned taking COWs and other medical equipment from room to room as part of the culture of the institution.

\section{Discussion}

Several isolation behaviors related to COW use by nurses in patient care were evaluated. The nurses in this study frequently interacted with the simulated patient in the isolation room, either by touching the patient or touching potentially contaminated surfaces in the room, before using their computer equipment. These actions have a high likelihood of contaminating the surfaces of the COW touched by the nurse. There is increasing attention on how human behaviors result in unintended contamination of surfaces in healthcare settings. Smith, Young, Robertson, and Dancer ${ }^{15}$ examined sequential hand-touch events of both hospital employees and 
hospital visitors using covert auditing methods. They found that the computer was one of the most frequently handled pieces of equipment. Hand touch events can only provide a theoretical explanation for the spread of organisms, but other studies have looked specifically at microorganisms found in certain kinds of hospital wards. Moore, Muzslay, and Wilson ${ }^{16}$ conducted a zonal analysis of predetermined surfaces for bacterial contamination in two different types of hospital wards and concluded that cleaning processes need to be specific to the likely areas of contamination. With increasing attention being focused on surface contamination in hospital rooms, nurses need to be more vigilant and aware of their behaviors that increase the possibility of spreading pathogens, both around an individual patient room and on items used from room to room.

Considerable variations in the processes for exiting the isolation room with a COW were noted in this study, which leads to questions about the correct procedures. Currently, there is no guidance for how to properly exit an isolation room with a COW, even though intuitively it is critical to wear new gloves to handle the contaminated COW after the dirty gloves, gown, and eyewear are removed. The application of hand sanitizer and then donning the new gloves in the room would be appropriate and logical, along with controlling the COW upon exiting the room and performing disinfection immediately upon closing the door. For airborne precautions, strictly adhering to the Centers for Disease Control and Prevention Guidelines ${ }^{17}$ would require the nurse or healthcare worker to remove the respirator outside the room, with the door closed, after the equipment disinfection so that the mask can be removed with washed hands, followed by a subsequent performance of hand hygiene a second and final time. This complicated process requires significant thought and training to execute properly. Furthermore, different levels of 
isolation would modify the process, as well, which adds another layer of complexity for the nurse providing patient care.

In this study, the nurses entered a simulated room with airborne and contact isolation precautions. With the risk of infectious particles lingering in the air, taking a COW into a patient room could contaminate all surfaces of the equipment, regardless of the nurse's actions while in the room. Upon exiting the room, the equipment would require thorough cleaning and disinfection. While some hospitals or patient units may have enough COWs to leave them in isolation rooms for an entire patient admission or have permanent computers at the bedside, it should be noted that this is not always the case. Moving a COW puts the nurse in a difficult situation, especially if the nurse-to-patient ratio is high or if the patient acuity is demanding. In real life situations critical patient needs logically take precedence and will be prioritized over the thorough cleaning of a COW. Based upon the cleaning behaviors demonstrated in this study, it appears that nurses primarily focus their cleaning efforts on high-touch surfaces and not on the entire device or COW. The finding that three nurses sent the contaminated COW out of the room, unsupervised, is also a concern in terms of the risk that a passerby might unknowingly touch contaminated surfaces of the COW while it is unattended.

The study is not without limitations. While the HD cameras are small, it is not possible to completely remove the Hawthorne effect. Participants may have been embarrassed or hyperaware of being videotaped, which could have altered their caregiving or COW cleaning performance. They may have also felt that because this was a simulation, the quality of their actions were not as important as it is in clinical practice. Conversely, the nurses may have performed better than they normally do in practice because they knew they were being monitored. Another limitation of this study was the lack of a responsive EMR on the COW. The 
lack of fidelity in using the COW may have altered some patterns of behavior for the nurses, particularly during the administration of the medication. The study included only nurses from one institution. There were no efforts to control for where the nurses received their formal instruction to become a registered nurse, and this information was not collected. The nurses who participated in the study were from various units within the hospital, so education related to disinfection of COWs may have varied amongst them.

Computer technology improves patient safety and reduces human error, but a COW at the bedside is not without infection control challenges. Specific education is needed for clinicians, healthcare workers, and housekeepers on best practices to clean and disinfect COWs, so that computer equipment which is intended to enhance patient safety, does not also serve as a distribution vehicle for hospital acquired infections. The findings in this study indicate that nurses are negotiating these challenges to the best of their ability, but there is a substantial need for more detailed guidance in the use and cleaning of mobile devices for care of an isolated patient. The findings from this secondary analysis of a research study using patient care simulation may also provide the basis for further work on the development and validation of proper scoring tools for the different types of transmission-based precautions in the evaluation of infection control behaviors related to COW use. These scoring tools could be utilized for both educational research and healthcare worker training. 


\section{References}

1. Neely AN, Weber JM, Daviau P, et al. Computer equipment used in patient care with a multihospital system: Recommendations for cleaning and disinfection. Am J of Infect Control 2005; 33: 233-237.

2. Rutala WA, White MS, Gergen MF, \& Weber DJ. Bacterial contamination of keyboards: Efficacy and functional impact of disinfectants. Infect Control Hosp Epidemiol 2006; 27:372-377.

3. Schultz M, Gill J, Zubairi S, Huber R, \& Gordin F. Bacterial contamination of computer keyboards in a teaching hospital. Infect Control Hosp Epidemiol 2003; 24:302-303.

4. Wilson APR, Hayman S, Folan P, et al. Computer keyboards and the spread of MRSA. J Hosp Infect 2006; 62:390-392.

5. Po JL, Burke R, Sulis C, \& Carling PC. Dangerous cows: An analysis of disinfection cleaning of computer keyboards on wheels. Am J of Infect Control 2009; 37: 778-780.

6. Otter JA, Yezli S, Salkeld JAG, \& French GL. Evidence that contaminated surfaces contribute to the transmission of hospital pathogens and an overview of strategies to address contaminated surfaces in hospital settings. Am J of Infect Control 2013; 41: S6S11.

7. Donskey CJ. Does improving surface cleaning and disinfection reduce health careassociated infections? Am J of Infect Control 2013; 41: S12-S19.

8. Sattar SA \& Maillard J. The crucial role of wiping in decontamination of high-touch environmental surfaces: Review of the current status and directions for the future. Am J of Infect Control 2013; 41: S97-S104. 
9. Fukada T, Iwakiri H, \& Ozaki M. Anaesthetists' role in computer keyboard contamination in an operating room. J Hosp Infect 2008; 70: 148-153.

10. Havill NL, Havill HL, Mangione E, Dumigan DG, \& Boyce JM. Cleanliness of portable medical equipment disinfected by nursing staff. Am J of Infect Control 2011; 39: 602604.

11. Beam, EL, Gibbs, SG, Hewlett, AL, Iwen, PC, Nuss, SL, \& Smith, PW. Method for investigating nursing behaviors related to isolation care. Am J of Infect Control 2014; 42: 1152-1156.

12. Schön D A. The Reflective Practitioner: How Professionals Think in Action. Basic Books: USA, 1983.

13. Ericsson K A, Simon H A. Protocol Analysis: Verbal Reports as Data (revised edition). MIT Press: Cambridge, 1993.

14. Beam E, Gibbs S, Boulter K, Beckerdite M, \& Smith PW. A method for evaluating personal protective equipment technique by healthcare workers. Am J of Infect Control 2011; 39: 415-420.

15. Smith SJ, Young V, Robertson C, \& Dancer SJ. Where do hands go? An audit of sequential hand-touch events on a hospital ward. J Hosp Infect 2012; 80:206-211.

16. Moore G, Muzslay M, \& Wilson APR. The type, level and distribution of microorganisms within the ward environment: A zonal analysis of an intensive care unit and a gastrointestinal surgical ward. Infect Control Hosp Epidemiol 2013; 34:500-506.

17. Centers for Disease Control and Prevention. Guideline for Isolation Precautions: Preventing Transmission of Infectious Agents in Healthcare Settings 2007. Available 
from http://www.cdc.gov/hicpac/2007ip/2007isolationprecautions.html. Accessed May

$17,2014$. 
Figure 1. Actual Image of Computer on Wheels (COW) used for study.

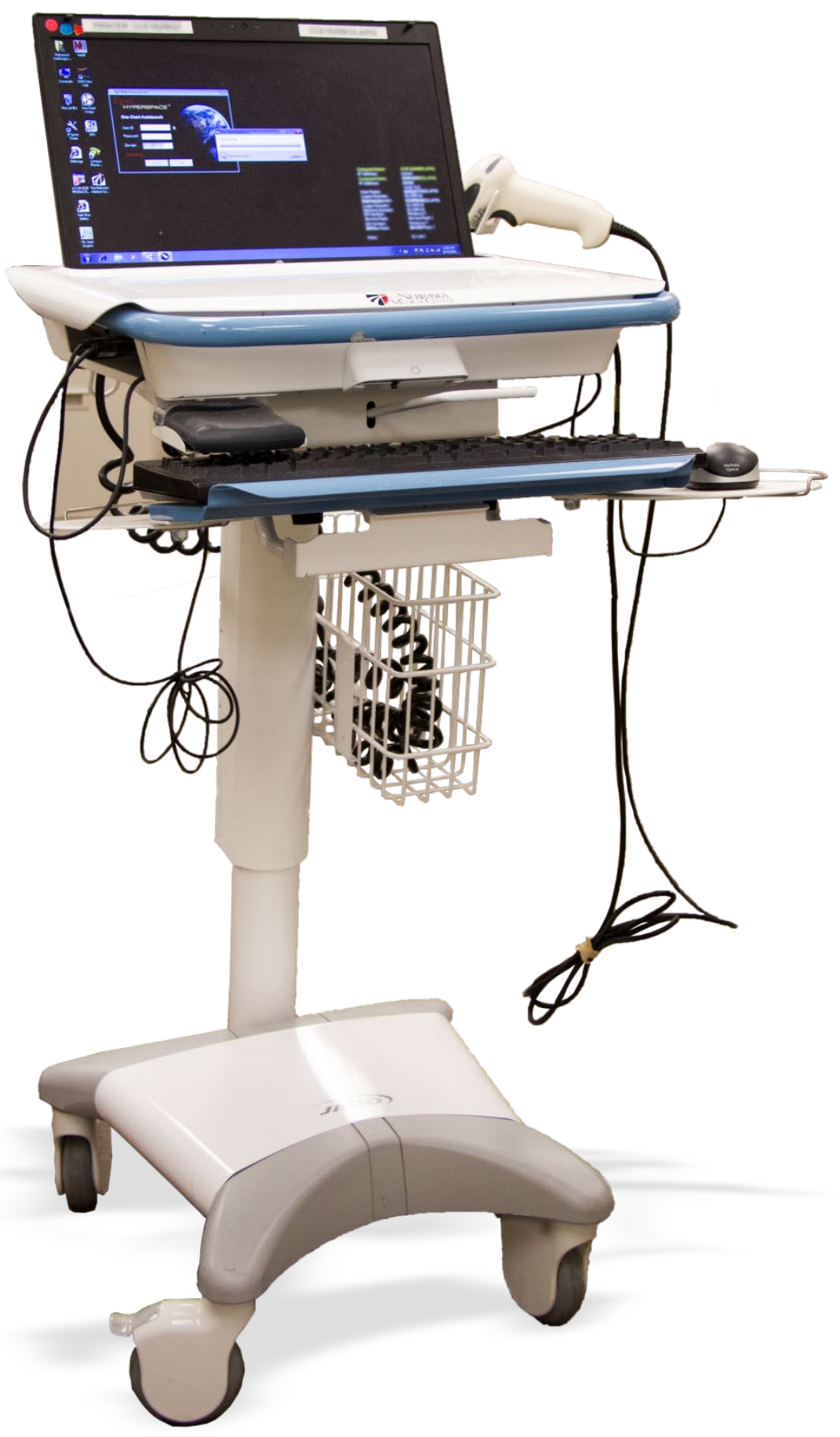


Table 1. Study Participant Demographics, $n=18$

\begin{tabular}{ll}
\hline Age & 32.3 years of age \\
Mean & 25 to 61 years of age \\
Range & \\
Degree & 16 \\
Bachelors of Science in Nursing & 1 \\
Associates Degree & 1 \\
Diploma Program & 10 \\
Years in Nursing & 5 \\
$<5$ & 1 \\
5 to 10 & 1 \\
11 to 15 & 1 \\
16 to 20 & 16 \\
$>20$ & \\
History of Bloodborne Pathogen Exposure & \\
Yes & \\
Nomale & \\
\hline Race & \\
\hline
\end{tabular}


Table 2. Computer on Wheels (COW) Room Exit and Disinfection Behaviors by Individual

\begin{tabular}{|c|c|c|c|c|c|c|c|c|c|c|c|c|c|c|c|c|c|c|c|c|}
\hline & \multicolumn{19}{|c|}{ Nurse Participant Behaviors by Individual $(\mathrm{n}=18)$} & Totals \\
\hline & 1 & 2 & 3 & 4 & 5 & 6 & & 7 & 8 & 9 & 10 & 11 & 12 & 13 & 14 & 15 & 16 & 17 & 18 & \\
\hline $\begin{array}{l}\text { COW } \\
\text { controlled on } \\
\text { exit }\end{array}$ & $\mathrm{X}$ & $\mathrm{X}$ & $\mathrm{X}$ & & & 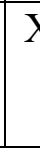 & & $\mathrm{X}$ & $\mathrm{X}$ & $\mathrm{X}$ & & $\mathrm{X}$ & $\mathrm{X}$ & $\mathrm{X}$ & $\mathrm{X}$ & $\mathrm{X}$ & $\mathrm{X}$ & $\mathrm{X}$ & $\mathrm{X}$ & 15 \\
\hline $\begin{array}{l}\text { Hand } \\
\text { hygiene } \\
\text { between } \\
\text { doffing } \\
\text { isolation PPE } \\
\text { and } \\
\text { disinfecting } \\
\text { COW: }\end{array}$ & & & & & & & & & & & & & & & & & & & & \\
\hline $\begin{array}{r}\text { Hand } \\
\text { Sanitizer }\end{array}$ & $\mathrm{X}$ & & & $\mathrm{X}$ & $\mathrm{X}$ & & & $\mathrm{X}$ & $\mathrm{X}$ & & & & $X$ & $\mathrm{X}$ & & & $\mathrm{X}$ & & $\mathrm{X}$ & 9 \\
\hline Handwashing & & $\mathrm{X}$ & & & & & & & & & & & & & & & & & & 1 \\
\hline Gloves & & & & & & & & & $\mathrm{X}$ & $\mathrm{X}$ & $\mathrm{X}$ & $\mathrm{X}$ & & & $\mathrm{X}$ & $\mathrm{X}$ & $\mathrm{X}$ & & & 7 \\
\hline $\begin{array}{l}\text { New gloves } \\
\text { obtained } \\
\text { from: }\end{array}$ & & & & & & & & & & & & & & & & & & & & \\
\hline In room & & & & & & & & & & $\mathrm{X}$ & & $\mathrm{X}$ & & & & & $\mathrm{X}$ & & & 3 \\
\hline $\begin{array}{l}\text { Isolation } \\
\text { cart }\end{array}$ & & & & & & & & & $\mathrm{X}$ & & $X$ & & & & $X$ & $X$ & & & & 4 \\
\hline $\begin{array}{l}\text { No } \\
\text { disinfection } \\
\text { of COW }\end{array}$ & & & & & & $\bar{x}$ & & & & & & & & & & & & $X$ & & 2 \\
\hline $\begin{array}{l}\text { Disinfection } \\
\text { of COW } \\
\text { outside room }\end{array}$ & $X$ & $\mathrm{X}$ & $\mathrm{X}$ & $\mathrm{X}$ & $\mathrm{X}$ & & & $\bar{X}$ & $\mathrm{X}$ & $\mathrm{X}$ & $X$ & $\mathrm{X}$ & $X$ & $X$ & $X$ & $\mathrm{X}$ & $\mathrm{X}$ & & $X$ & 16 \\
\hline
\end{tabular}


Table 3. Surfaces of Computer on Wheels (COW) disinfected by Nurse

\begin{tabular}{|l|l|l|l|l|l|l|l|l|l|l|l|l|l|l|l|l|l|l|}
\hline & \multicolumn{10}{|c|}{ Nurse Participant Behaviors by Individual (n $=18)$} \\
\hline & 1 & 2 & 3 & 4 & 5 & 6 & 7 & 8 & 9 & 10 & 11 & 12 & 13 & 14 & 15 & 16 & 17 & 18 \\
\hline $\begin{array}{l}\text { Disinfected } \\
\text { COW surfaces: }\end{array}$ & & & & & & & & & & & & & & & & & & \\
\hline Mouse & $\mathrm{X}$ & & $\mathrm{X}$ & $\mathrm{X}$ & $\mathrm{X}$ & & & $\mathrm{X}$ & $\mathrm{X}$ & $\mathrm{X}$ & $\mathrm{X}$ & $\mathrm{X}$ & $\mathrm{X}$ & $\mathrm{X}$ & & $\mathrm{X}$ & & $\mathrm{X}$ \\
\hline Wand & $\mathrm{X}$ & & $\mathrm{X}$ & $\mathrm{X}$ & $\mathrm{X}$ & & $\mathrm{X}$ & $\mathrm{X}$ & $\mathrm{X}$ & $\mathrm{X}$ & $\mathrm{X}$ & $\mathrm{X}$ & $\mathrm{X}$ & $\mathrm{X}$ & & $\mathrm{X}$ & & $\mathrm{X}$ \\
\hline Keyboard & $\mathrm{X}$ & $\mathrm{X}$ & $\mathrm{X}$ & $\mathrm{X}$ & $\mathrm{X}$ & & $\mathrm{X}$ & $\mathrm{X}$ & $\mathrm{X}$ & $\mathrm{X}$ & $\mathrm{X}$ & $\mathrm{X}$ & $\mathrm{X}$ & $\mathrm{X}$ & & $\mathrm{X}$ & & $\mathrm{X}$ \\
\hline Screen & & $\mathrm{X}$ & & $\mathrm{X}$ & $\mathrm{X}$ & & & & $\mathrm{X}$ & $\mathrm{X}$ & $\mathrm{X}$ & & $\mathrm{X}$ & & & & & $\mathrm{X}$ \\
\hline Cart (base) & & & & & $\mathrm{X}$ & & & & & & & & & & & & & \\
\hline Cords & & & $\mathrm{X}$ & & $\mathrm{X}$ & & & & & & & $\mathrm{X}$ & $\mathrm{X}$ & & & & & $\mathrm{X}$ \\
\hline Cart top & $\mathrm{X}$ & $\mathrm{X}$ & $\mathrm{X}$ & $\mathrm{X}$ & $\mathrm{X}$ & & $\mathrm{X}$ & $\mathrm{X}$ & $\mathrm{X}$ & $\mathrm{X}$ & $\mathrm{X}$ & $\mathrm{X}$ & $\mathrm{X}$ & $\mathrm{X}$ & $\mathrm{X}$ & $\mathrm{X}$ & & $\mathrm{X}$ \\
\hline
\end{tabular}

